\title{
Flood Inundation Mapping of Jigjiga-Town and Its Surrounding Environment: Using GIS \& HEC-RAS Model
}

\author{
Abirham Cherinet ${ }^{1,}$, , Sadnur Worku ${ }^{2}$ \\ ${ }^{1}$ Climate Science Research Department, Ethiopian Environment and Forest Research Institute, Addis Ababa, Ethiopia \\ ${ }^{2}$ Geotechnical Investigations, Ethiopian Construction, Design and Supervision Works Corporation, Addis Ababa, Ethiopia
}

\section{Email address:}

aberham2010@gmail.com (A. Cherinet)

${ }^{*}$ Corresponding author

\section{To cite this article:}

Abirham Cherinet, Sadnur Worku. Flood Inundation Mapping of Jigjiga-Town and Its Surrounding Environment: Using GIS \& HEC-RAS Model. International Journal of Environmental Protection and Policy. Vol. 9, No. 2, 2021, pp. 40-49. doi: 10.11648/j.ijepp.20210902.14

Received: February 15, 2021; Accepted: March 24, 2021; Published: April 20, 2021

\begin{abstract}
Flood is one of the natural hazards that have negative impacts on peoples and property. It occurs in lowland areas without any sign when excessive rains fall in adjacent highland areas. Since flood is unavoidable natural phenomena, adopting protective mechanisms are crucial. This study was conducted in Jigjiga town, Eastern Ethiopia with main objective of delineating flood risk areas. For the purpose of flood risk mapping preparation, hydrology and hydraulics models have been used. Besides, land use /cover change detection analysis has been carried out between the year 2003 and 2017 . Soil Conservation System (SCS) Curve Number method was used as hydrology model. Satellite and field data have been collected, filtered and finally a geo-database has been developed in GIS environment. Flow data and river geometry data, which obtained from hydrology model and prepared using HEC-GeoRAS was used as inputs for HEC-RAS model. Before running steady flow analysis, correction of geometry data has been carried out in HEC-RAS environment. From the study, it was found that, expansion of built up area and agricultural land at the cost of open area. Flood inundation extent maps show that increasing in aerial coverage as return period increases but the variation in area between consecutive periods are small. The flood extent obtained by applying structural flood control mechanism shows that the measure reduces the flood extent considerably but it also exhibits some part of the town is still in undated in all return periods. From the analysis it was observed that the increases in built up area and agricultural land may lead to increase flooding. Besides, among the LULC classes fall under high risk zone at different return periods, built up area and agricultural land consist a considerable proportion. It also observed that, flood risk areas increase as return period increases but the variation between the periods is small. The flood risk map can be used for planning control measures for future flood.
\end{abstract}

Keywords: Flood Mapping, GIS, HEC-GeoRAS, HEC-RAS, Soil Curve Number

\section{Introduction}

Flood can be explained as the over-flowing of water out of the normal confines of a stream or other body of water, or the accumulation of water by drainage over areas that are not normally submerged [1]. Flood is among one of the natural disasters occurring worldwide since time immemorial. According to Sisir \& Balan [2], it has been ranked "first" out of sixteen natural disaster types that brought damages on properties. It is responsible for the loss of more than 20,000 lives per year and adversely affecting about 75 million people worldwide [3]. Several different types of floods occur worldwide but it can be helpful to differentiate between two general categories of flood according to the size of the affected area and the duration of precipitation (spatial and temporal scale of flood events). These are flash flood and reverie flood [4]. The former is generally defined as a rapid onset of flood with a short duration and a relatively high peak discharge. It occurs rapidly, mostly after within six hour of rainfall [5]. While the later can be expressed as the excess amount of water over flow from a well-define driver channel or stream.

Flash flood is a common phenomenon in Jigjiga watershed and may be associated with land use/cover change, urbanization, population growth and poor design of drainage 
system. Since it is impossible to avoid flooding and its damage, developing protecting mechanisms are crucial. According to [6] suggestion, the availability of spatial data coupled with hydrologic and hydraulic models, Geographical Information System (GIS) appears to be excellent environment for developing water resource planning and management. For this purpose, it is important to focus on flood risk mapping. Equally, flood mapping is effective when combined with GIS and Remote Sensing technology integrated with hydraulic model [7] to map inundation areas as well as to prepare flood risk map.

\subsection{HEC-RAS (Hydrologic Engineering Center River Analysis System)}

HEC-RAS is an integrated system of software, designed for interactive used in a multi-tasking, multi-user network environment. The system is comprised of a graphical user interface (GUI), separate hydraulic analysis component, data storage and management capabilities, graphic and reporting facilities. The model is designed to perform one dimensional (1D), two-dimensional (2D), or combined 1D and $2 \mathrm{D}$ hydraulic calculation for a full network of natural and constructed channels. HEC-RAS discovers specific viable application in floodplain mitigation measures [8].

\subsection{Land Use \& Land Cover Condition of the Study Area}

The land use land cover of Jigjiga town and its surrounding watershed had changed rapidly due to population pressure, urbanization, fuel wood extraction, agricultural land expansions and overgrazing [9, 10]. The expansion of built up area in the town and agricultural land in the watershed are the most drivers of the land use land cover change dynamics of the study area. Agricultural land, bare land, shrub/bush/tree, grass land, built up area and water body are the major land use land cover classes exist in the area.

\section{Materials and Methods}

\subsection{Study Area Description}

The study area is located within the Shebelle Basin, Jigjiga town, and its area is about 8500 ha. It is located at $9.420 \mathrm{~N}$ to 9.270 N latitude and 42.740 E to $42.840 \mathrm{E}$ longitudes (Figure 2). The elevation of the study area ranges from $1597 \mathrm{~m}$ to $1750 \mathrm{~m}$ above mean sea level. The Shebelle Basin includes the Jigjiga sub-watershed, whose tributaries originate from the upper escarpments of the Bale Mountains and West Hararghe of Oromiya National Regional State (ONRS) and the highland parts of Ethiopian Somali Regional State.

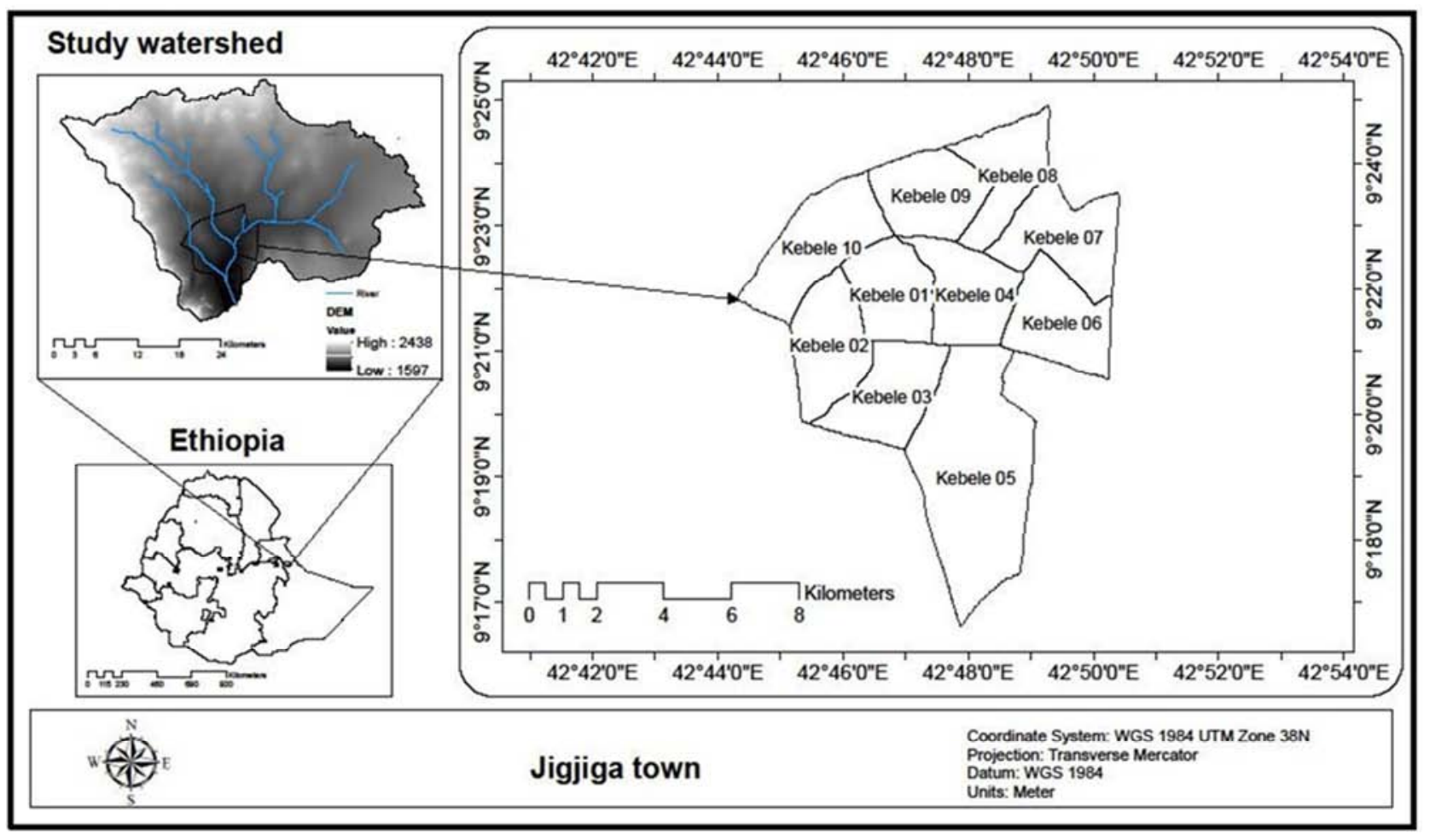

Figure 1. Location map of the study area.

Based on projections made by the Central Statistical Agency [11], the 2017 population of Jigjiga town has been estimated at about 169,390 (Ministry of Urban Development, Housing and Construction, 2015). The mean monthly temperature of Jigjiga town varies from $15.2^{\circ} \mathrm{C}$ to $27.73^{\circ} \mathrm{C}$ in
December and April respectively. The hottest month is May while December is the coldest month. The average annual temperature of the town is $20.4^{\circ} \mathrm{C}$. The mean annual rainfall of Jigjiga town is $523.48 \mathrm{~mm}$. The mean monthly amount of rainfall varies between $7.13 \mathrm{~mm}$ and $103.11 \mathrm{~mm}$ in 
December and April respectively (NMA, 1984- 2016).

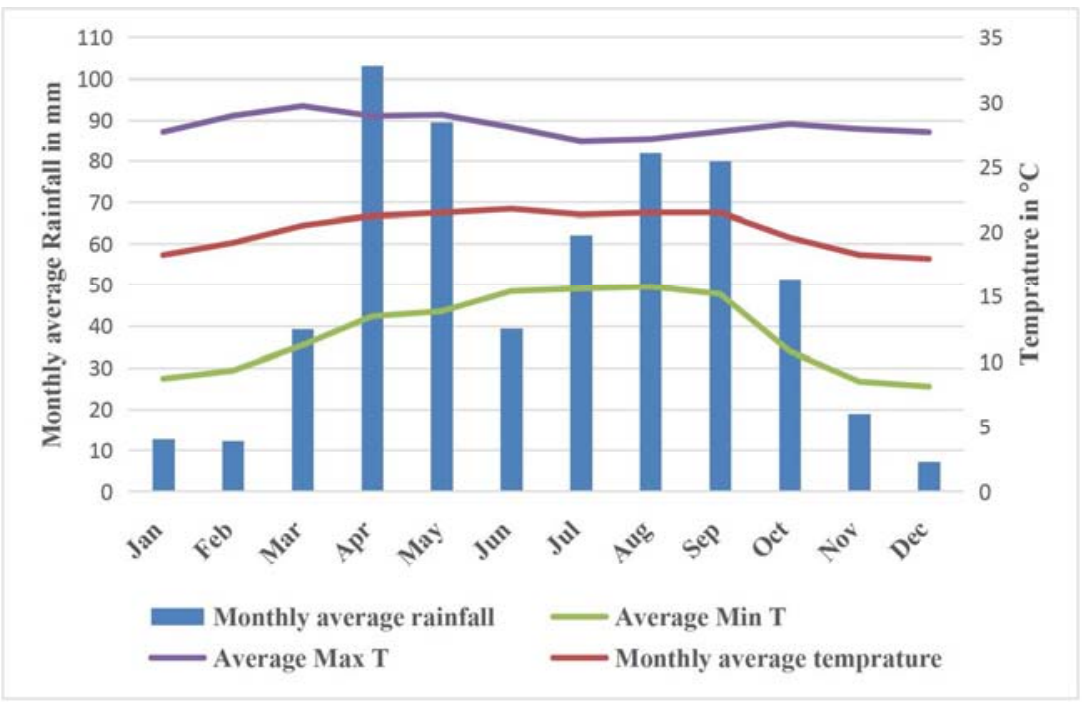

Figure 2. Monthly average rainfall along with temperature from 1984-2016.

\subsection{Methods}

The study used SCS-CN method, which developed by National Resources Conservation Service (NRSC), United States Department of Agriculture (USDA) in 1969, as hydrological model. Input data for this model comprise rainfall data, study area watershed, soil type and land use/cover maps. Historical rainfall data, which was collected in the past 32 years, were fitted with Gumbels' distribution [12] and extreme precipitation at different return periods $(10,25,50$ and 100 years) were calculated. Basins delineation was done using Hydraulic Engineering Center-Geospatial Hydrologic Modeling Extension (HEC-GeoHMS), which is an extension, to ESRI'S ArcGIS software [13]. Digital Elevation Model with $30 \mathrm{~m}$ resolution and DEM from digitized contour $(20 \mathrm{~m})$ were used to derive the basin. Systematic procedures were followed to delineate study area watersheds. Steps in the analysis include filling depression, calculating flow direction and flow accumulation, delineating, defining and segmenting streams, delineating watershed, processing watershed polygons, processing streams and aggregate watersheds. Further, the generated sub-basins and streams were refined by applying an outlet that was selected at the downstream side. SCN is based on hydrologic soil group and land use/cover data. The study area soil group map and land use /cover map were overlapped. The $\mathrm{CN}$ values for different land uses and hydrologic soil groups were adopted from Technical Release 55 Urban Hydrology for Small watersheds [14]. Then, the CN of each sub-basin was calculated using weighted average technique. Lastly, using SCS-CN formula, each sub-basin runoff in $\mathrm{m}^{3} / \mathrm{s}$ was calculated.

\subsection{Geometric Data Preparation}

Data required for the Hydraulic model included: Grid, river geometry and discharge. Hydraulic Engineering Center - Geospatial River Analysis System (HEC-GeoRAS) used for the preparation of river geometry [15] and later this geometry data edited in the HEC-RAS model. After geometry preparation, a GIS import file to Hydraulic Engineering Center - River Analysis System (HEC-RAS) was created using RAS Geometry menu (Export RasDATA). HEC-RAS processing was the next step. Here, first, flow data for different return periods obtained from the hydrology model entered in the HEC-RAS model. Then, boundary condition was assigned (Normal depth) to begin the starting water surface at the end of river system (downstream). Running the model and exporting output results into Arc GIS were the next steps. Finally, HEC-RAS post processing which included importing RAS data, water surface generation and inundation mapping carried out (HEC-RAS user's manual version 5.0, 2016).

\subsection{Model Development}

HEC-RAS is an integrated system of software that can simulate the water flow in rivers and channels using a numerical model. Most importantly, HEC- RAS model is used to estimate the water surface profiles of flash flood events to simulate and create flood inundation maps. All RAS layers like; stream center line, banks (lines and stations), flow path center lines, cross-section cut lines, and others were generated from DEM or triangular irregular networks (TIN). Flow data of the river was entered to the model corresponding to the return periods and also, manning coefficient of the main channel, leftover bank and right over bank, contraction coefficient, expansion coefficient and boundary condition were entered to the new HEC RAS project developed step by step as per the HEC- RAS manual, to simulate steady-state flow successfully. The output data quality was checked by graphical cross sections editor tool for each cross-section. After modeling in HEC-RAS, results were interred into Arc View and by using HEC-geoRAS and cross-section tools extensions, flood zones and its areas was extracted. After the extraction the inundated 
area was delineated using the water surface data, and the DEM created for the basin. Finally, floodplain mapping was done by exporting output of HEC -RAS to HEC- Geo RAS Arc GIS extension.

\section{Results \& Discussions}

\subsection{Hydraulic Model Result}

The main input of hydraulic model has been prepared using HEC-GeoRAS and ArcGIS. Based on derived Grid from contour, data generated from hydrology model, and data collected from field, river geometry was generated. In this manner, many variables can defined in HEC RAS software. By inputting flow data into HEC RAS, water surface profiles and flood characteristics (inundation areas, flow depths and velocities, flow area and volume etc) are derivable for steady/unsteady flow. Most important factors of flood risk assessment are inundation area, flow depth and velocity. The model is made prepared to run for steady flow state by making required editing of input data and entering flow data. Profiles of streams; rating curves; flow depths and velocities; flow areas, widths and volumes; and water surfaces of cross sections besides of flood inundation outputs are also obtained by HEC RAS.

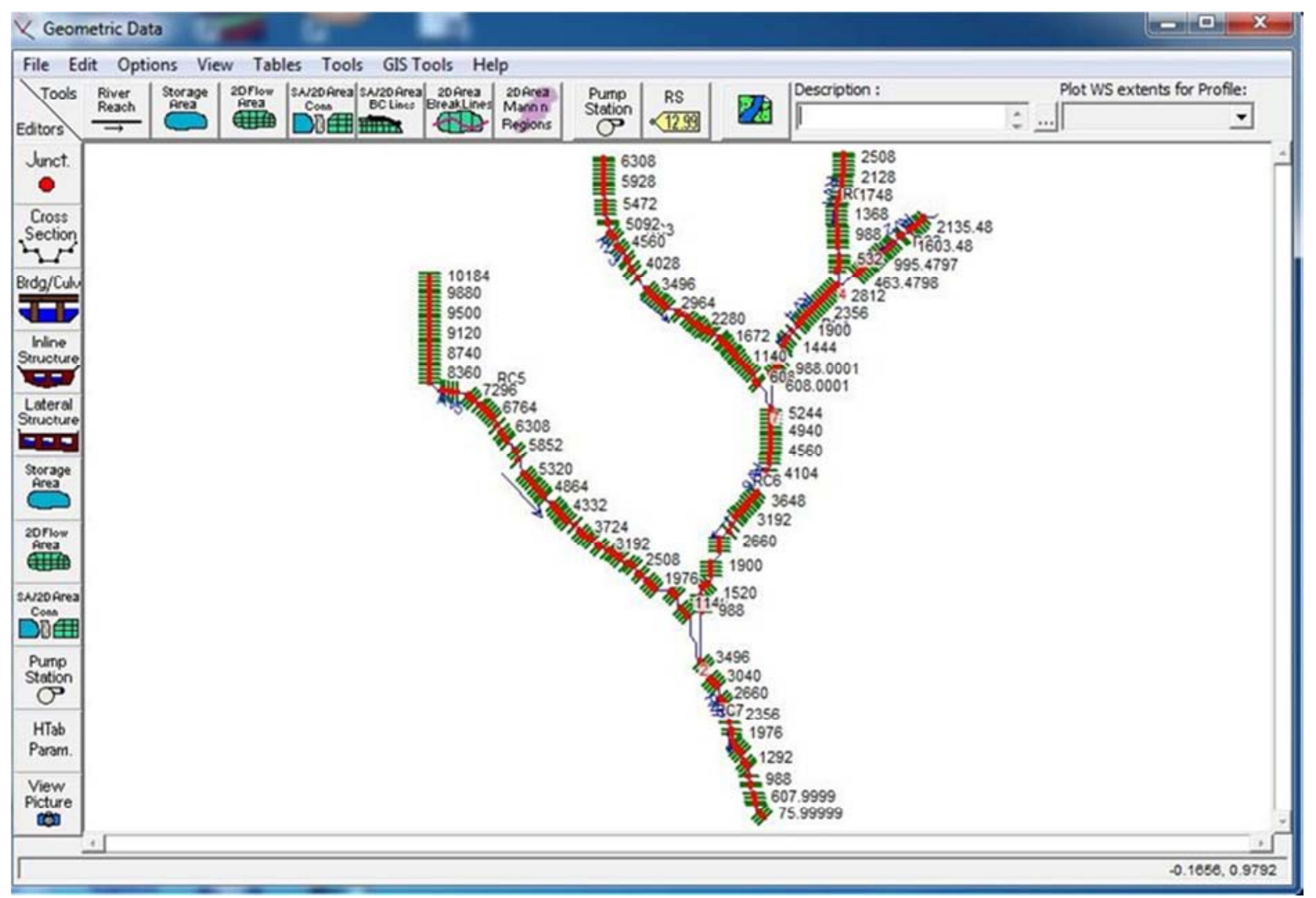

Figure 3. Geometric data imported from HEC-GeoRAS.

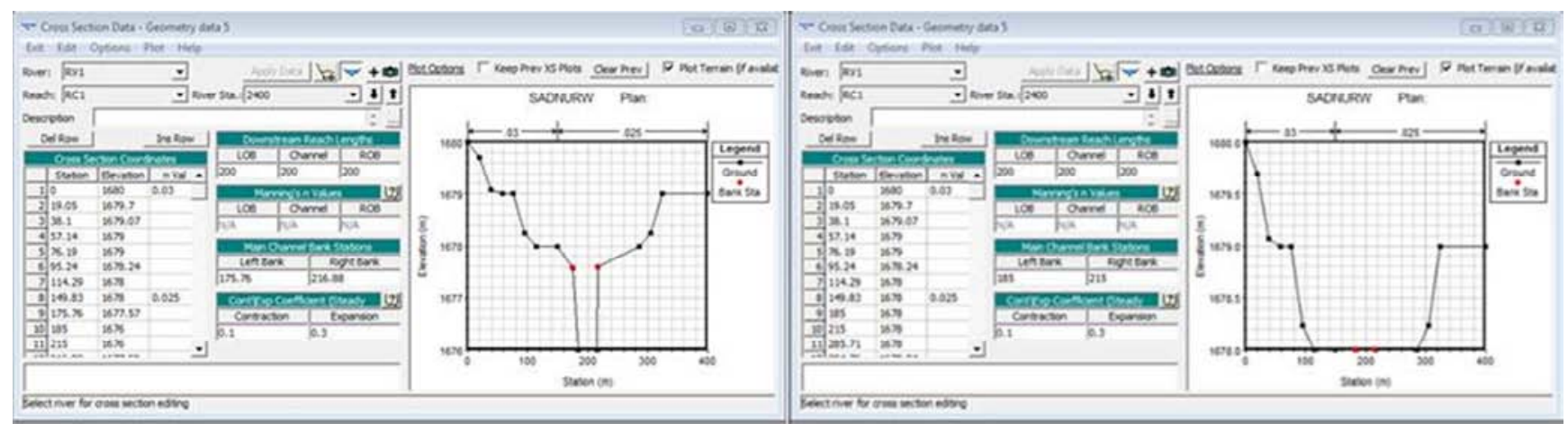

Figure 4. Cross-section after and before editing.

\subsection{Flood Plain Maps Result}

Steady-flow simulations performed for return periods of $10,25,50$ and 100 years and flood inundation extents for different return periods were generated (Figures $2 \mathrm{a}$ and $2 \mathrm{~b}$ ). The flood plain map shows that $6.6 \%$ of Jigjiga town inundated by a 100 -year flood. About $6.4 \%, 6.2 \%$ and $5.8 \%$ 
areas were covered by 50, 25 and 10 years flood respectively. The area inundated by different return periods more or less similar but slight increasing in aerial coverage observed as return period increases. Similarly, flood depth of all return periods is found to be high at downstream of the junction of river 3 and 4, within Kebele 5. This is because of that, kebele
Keble 5 is found at lower elevation as compared to other kebeles and bare and agricultural lands covered about 980 ha. and 590 ha. respectively, which are relatively high as compared to other kebeles. On the other hand, in the remaining Kebeles, most of the inundated area has a water depth of below $1.5 \mathrm{~m}$.

Table 1. Area of flood zoning at different return period.

\begin{tabular}{lllll}
\hline Return Period (year) & $\mathbf{1 0}$ & $\mathbf{2 5}$ & $\mathbf{5 0}$ & $\mathbf{1 0 0}$ \\
\hline Area $\left(\mathrm{m}^{2}\right)$ & $4,950,537$ & $5,255,905$ & $5,442,457$ & $5,621,263$ \\
\hline
\end{tabular}

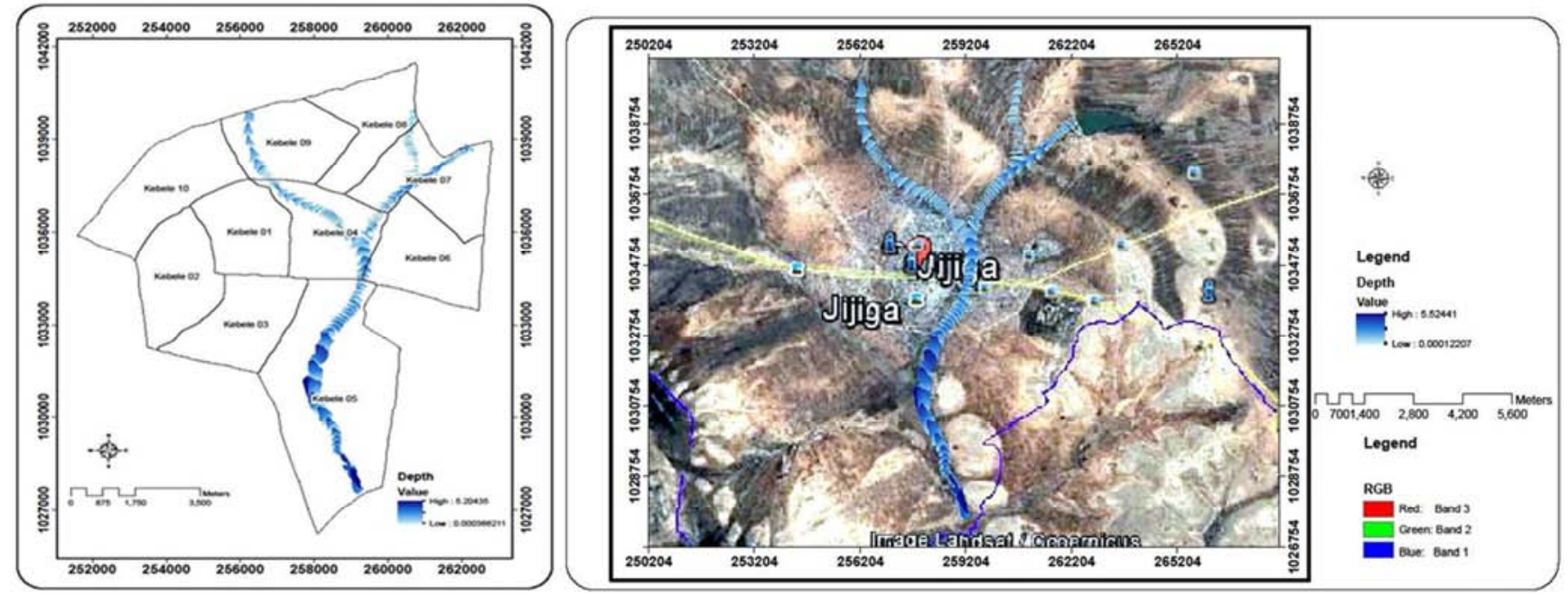

Figure 5. Flood inundation map of 10 and 100-year return period respectively.

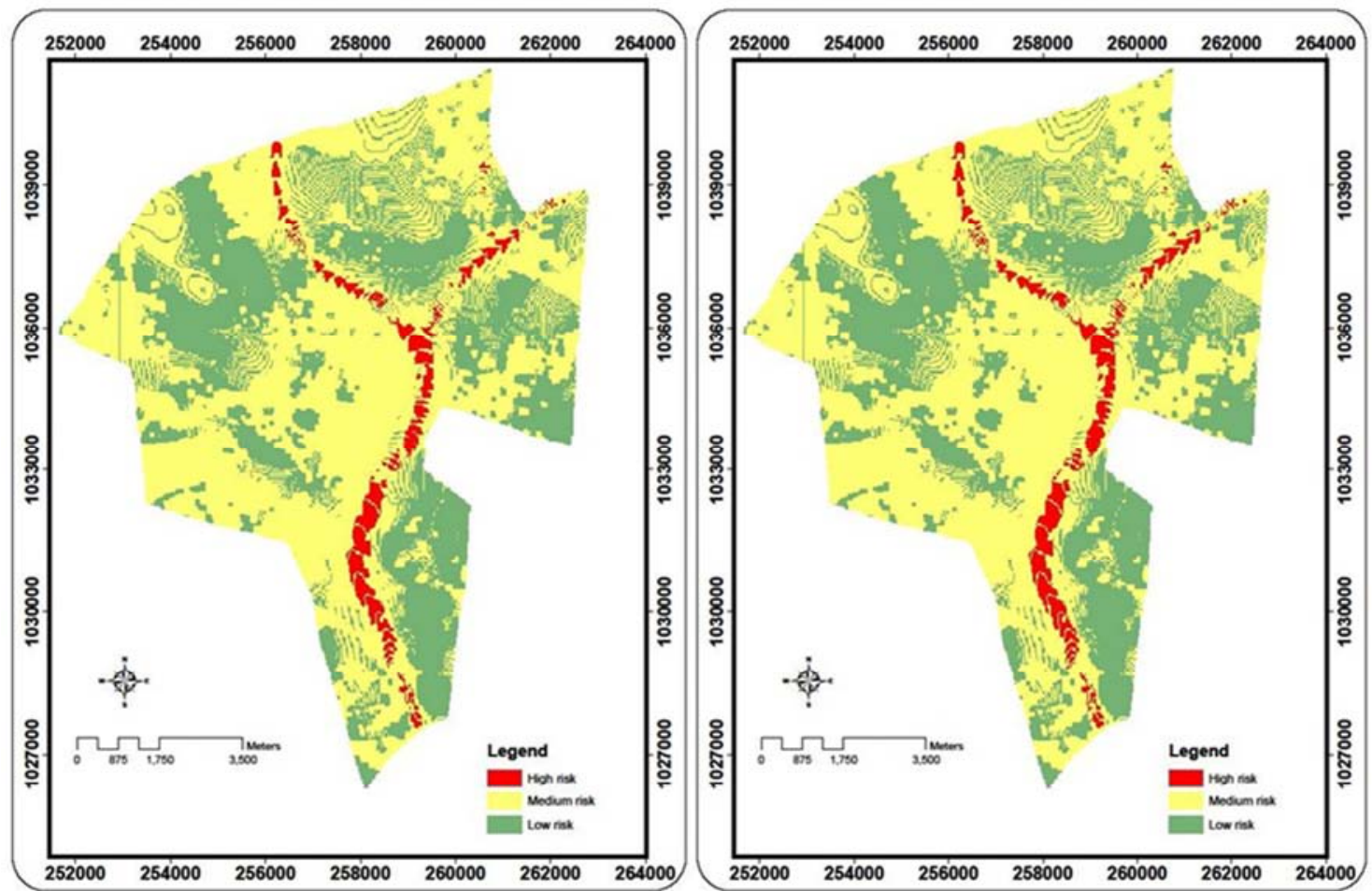

Figure 6. Flood risk map of 10 and 100 year return period respectively.

\subsection{Flood Risk Map of the Study Town and Watershed}

The risk map result of 10-year return period (Figure 6) shows that about $3,018,399 \mathrm{~m}^{2}$ area falls under high risk flood, which accounts $3.56 \%$ of the Jigjiga town. Among the parts falls on high-risk flood, built up area and agricultural land covered about 955,099 $\mathrm{m}^{2}$ and 1,180,816 $\mathrm{m}^{2}$ 
respectively. About 1,027,116 $\mathrm{m}^{2}$ area covered by shrub/bush/tree and grass land also falls under 10-year flood risk. Similarly, the high-risk area in the case of 100 -year flood (Figure 6b) is about 3,384,725 $\mathrm{m}^{2}$ of which 1,052,922 $\mathrm{m}^{2}$ and $1,311,431 \mathrm{~m}^{2}$ areas are covered by built up and agricultural land. In the remaining flood risk maps, 25 and 50 years return periods; high risk areas occupied about $3.75 \%$, and $3.87 \%$ of the study town respectively. The flood risk maps of all return periods $(10,25,50$ and 100 years) reveled that about $60 \%$ of Jigjiga town falls under medium flood risk and low flood risk area covered more than $30 \%$ of the town.

\subsection{Land Use Land Cover Change and Flood Risk}

It is obvious that population growth has a direct impact on urban expansion. In this case, when the projected population of the Jigjiga town in 2001 was 72,585, the built up area of the town in 2003 was $5.86 \mathrm{~km}^{2}$. The population was increased to 169,390 in 2017 , likewise the built up area was expanded to $14.01 \mathrm{~km}^{2}$. Rapid level of urbanization can create unplanned growth of a city and this will have an impact on the residences such as exposure to flooding and lack of infrastructure [16]. Similarly, there is field evidence that agricultural land increases may cause local flooding [17]. Land use /cover change detection analysis of Jigjiga town shows that built up and agricultural land were increased by more than $100 \%$ and $36.91 \%$ respectively. Similarly, agricultural land and built up area of the study watershed increased by $57.7 \%$ and $89.5 \%$. The increase in built up area and agricultural land can be associated with flooding. Agricultural land increase may lead to flooding by increasing imperviousness through compaction of top soil while cultivating either using machinery or traditional ways or by clearing shrub lands for the purpose of agriculture. On the other hand, flooding significantly affects agricultural production by damaging crops as well as production lands. In similar manner, built-up area may lead to flooding by increasing imperviousness. Similarly, the decrease in vegetation cover can also be associated with flooding.

\subsection{Model Validation and Accuracy Assessment}

By comparing flood area mapped in the field (Figure 7) and HEC-RAS inundation result (Figure 8), model evaluation has been carried out. Total area correctly predicted by the model is $66 \%$, whereas areas over and under predicted by the model are $34 \%$ and $40 \%$ respectively. The accuracy of simulated flood extent is provided in Table 2. It can be noticed that the model omission and commission errors are high. The area under predicted and over predicted by the model is considerable and it accounts about $34 \%$ and $40 \%$ respectively. This is due that the model used relatively low resolution DEM and at the same time, rainfall amount used in the simulation model obtained from TAM Satellite could be over or under estimated. Additionally, observed flood extent, which mapped on site, negatively affects those errors.

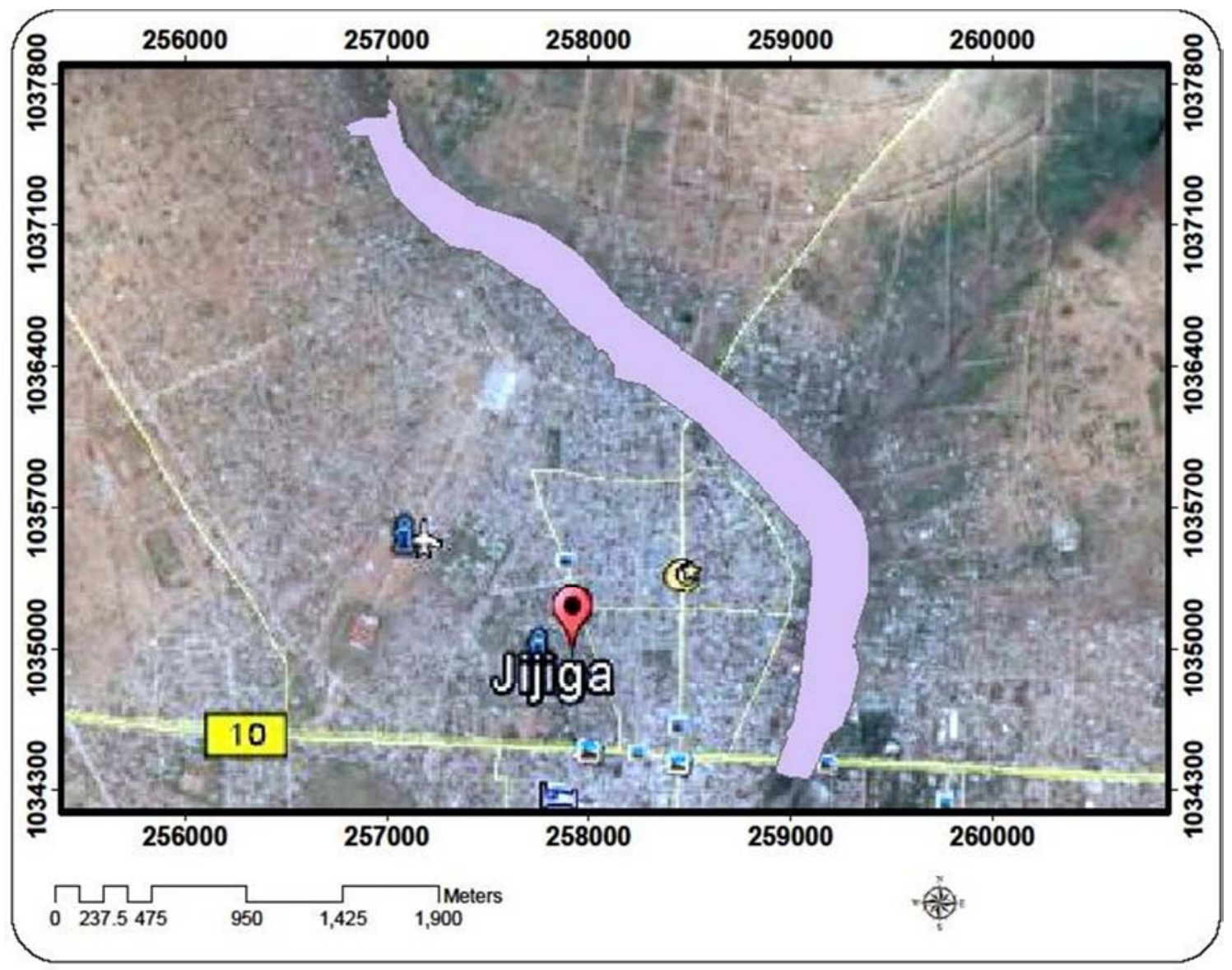

Figure 7. Observed flood extent, April 5, 2016 with Google Earth image. 


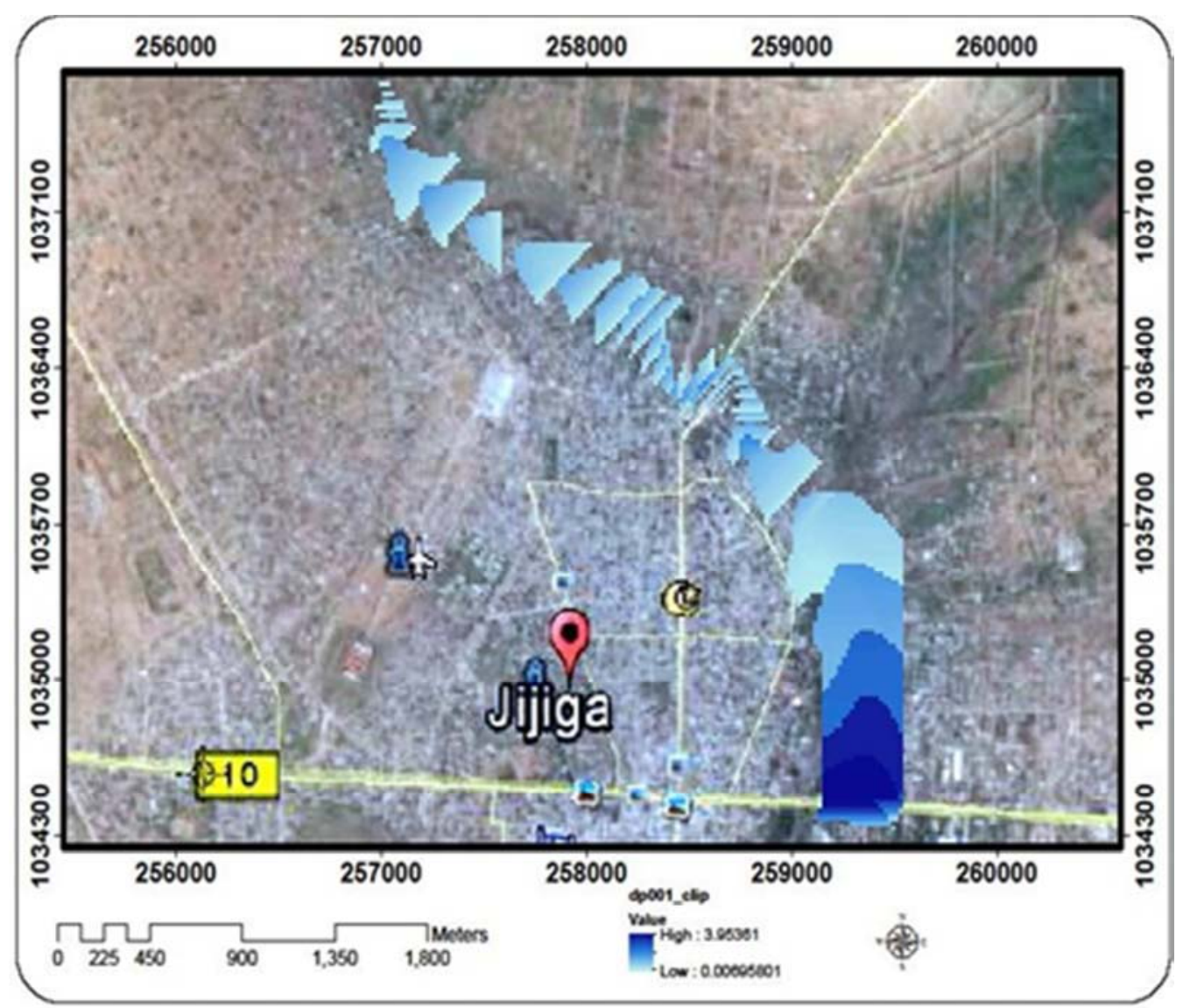

Figure 8. Simulated flood extent with Google, Earth image.

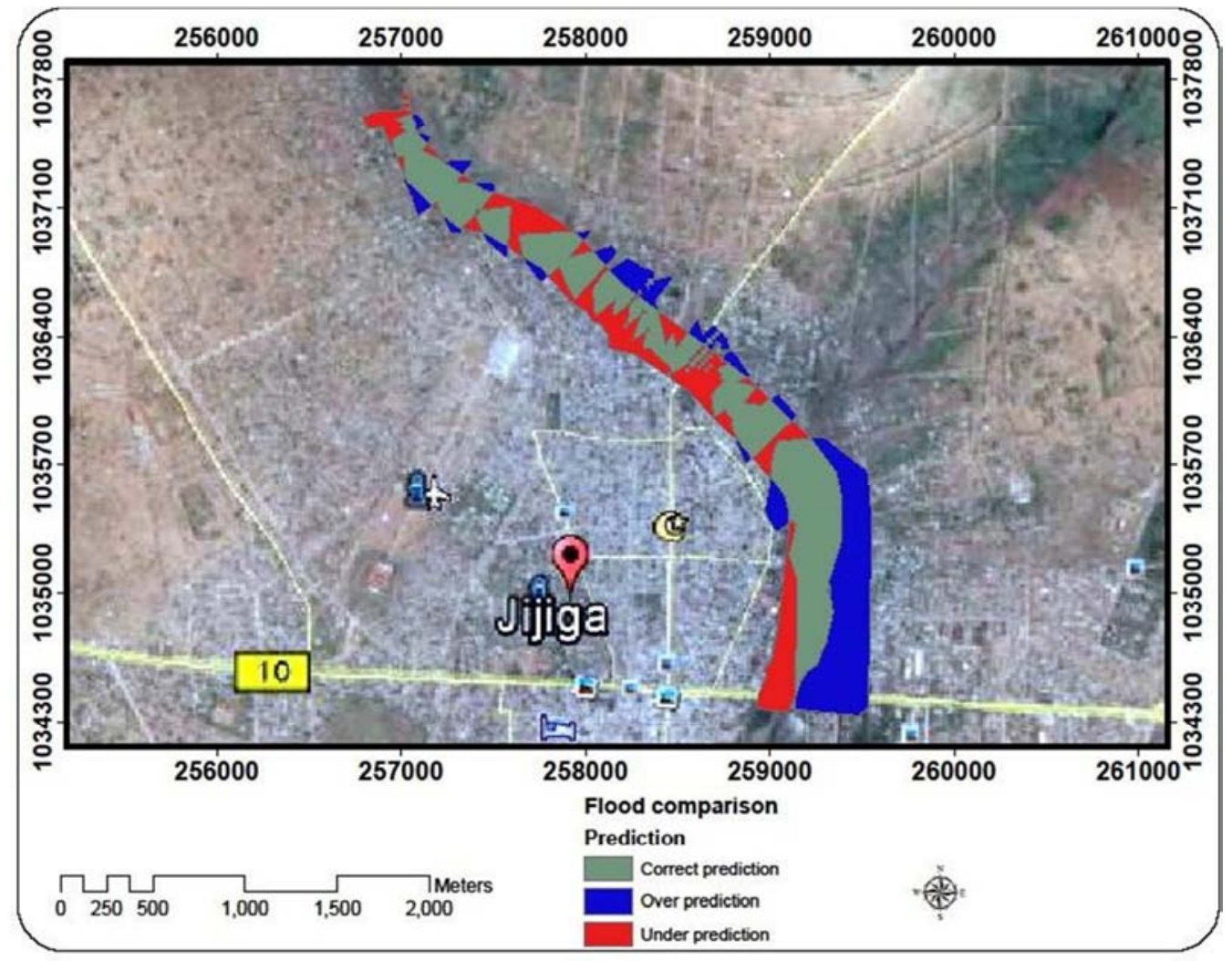

Figure 9. Comparison of flood extents with Google Earth image. 
Table 2. Accuracy assessment of simulated flood.

\begin{tabular}{ll}
\hline Measures of Accuracy (in \%) & Formulation \\
\hline Simulated Flood Extent Accuracy & $\frac{F_{c p}}{F_{c p}+F_{u p}} \times 100=\frac{729676 m^{2}}{729,676 m^{2}+381,153 m^{2}} \times 100=66 \%$ \\
Error Of Omission & $\frac{F_{u p}}{F_{c p}+F_{u p}} \times 100=\frac{381,153 m^{2}}{729,676 m^{2}+381,153 m^{2}} \times 100=34 \%$ \\
Error Of Commission & $\frac{F_{o p}}{F_{c p}+F_{o p}} \times 100=\frac{485,221 m^{2}}{729,676 m^{2}+485,221 m^{2}} \times 100=40 \%$ \\
\hline
\end{tabular}

\subsection{Future Scenario}

Recently, the Ethiopian Somali Region Unban Development Construction and Industry Bureau (SRUDCIB) has conducted study to come up with immediate flood protection and safeguard measures; primarily the construction of retaining flood blockage Retaining Wall on the Jarer (Toga) river Stream along the city planning boundary. The hydraulic model result of this study proposed

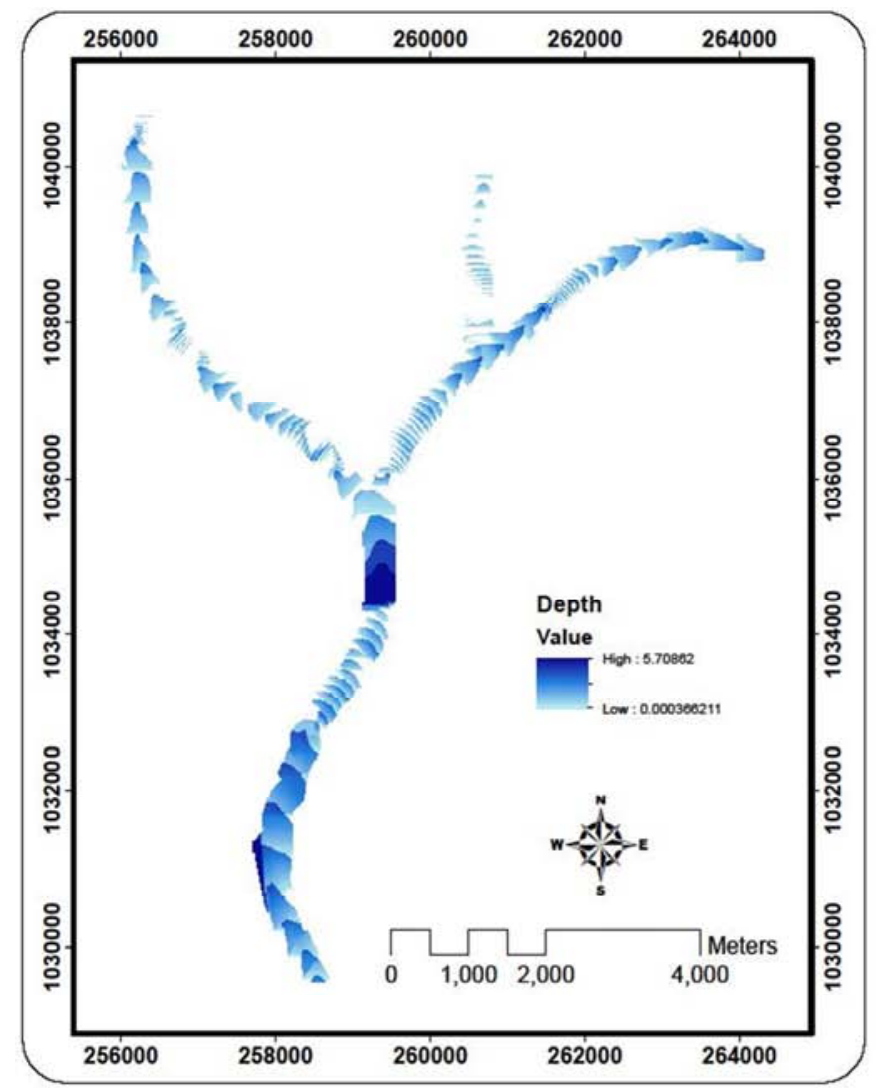

that, retaining wall with $4 \mathrm{~m}$ height along with $30 \mathrm{~m}$ width channel needs to construct to accommodate the flood. When we evaluate this structural flood mechanism using HEC-RAS model by applying a $4 \mathrm{~m}$ height and $30 \mathrm{~m}$ width channel, this structural measure will decreases the 10 -year return period flood extent by $69 \%, 25$-year return flood extent by $62 \%, 50$ year return period by $56 \%$ and 100 year return period by $51 \%$. The water depth also decreased considerably.

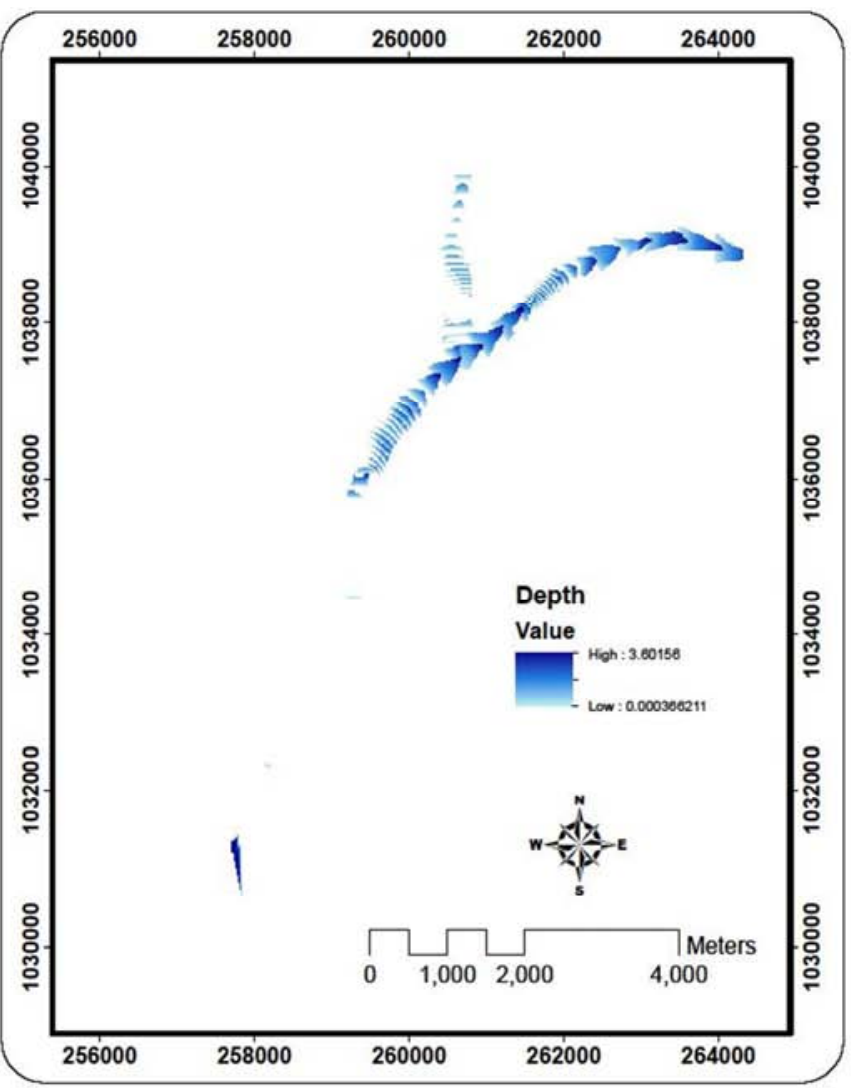

Figure 10. Flood inundation extent of 10-year return period before applying structural measure and after applying structural measure respectively.

\section{Conclusions}

In this study, HEC-RAS model integrated with Arc-GIS was used to map the flood inundation area of Jigjiga town and its environment. Mapping a floodplain requires a forecasting of the behavior of the stream in question for various recurrence interval storm events and the ability to translate the forecasted results into a plan-view extent of flooding. 32 years of precipitation data, flow data, digital elevation data, land use and soil data were used to analyze the flood condition of the area. SCS CN loss method was used to simulate the rainfall runoff relationship. Finding of this research showed that, HEC-GeoRAS and HECGeoHMS can be utilized for preparation of input geometric data for HEC- RAS hydraulic model and HECHMS hydrological model respectively, and also for visualization of the hydraulic model results but they required high resolution Digital Elevation Model. Flood 
risk will be depends on the land use condition of the area. Expansion of built up areas led to increase flood risk areas since in the past most of the people were less vulnerable to flood risk due to their land use system was out of flood risk areas but recently people have started to use flood risk areas. The simulation model shows that the town is sensitive to small return period flood (10 year). The flood plain map extent increases as return period increases. However, the variations are small due to flat and narrow river that can't cop up even a 10-year return period flood. The results also highlighted the vulnerability of the study area, especially heavily urbanized areas, to the occurrence of floods, which represent a serious risk to the safety of the population and infrastructure.

\section{Recommendations}

Flood risk can be reduced by adoption of non-structural measures, which include early warning, and the development of land use/cover planning. Relocating settlements prone to high flood risk could reduce hazard created by flooding. Similarly, by protecting development in those risk areas the same result can be obtained as relocating. Creating awareness to residents who live in high flood risk area would help when evacuation plan implemented during flooding. The structural measure that designed by Ethiopian Somali Region Unban Development Construction and Industry Bureau (SRUDCIB) decrease the flood extent considerably but it did not fully control the flood. Therefore, the hydraulic model result of this study proposed that, retaining wall with $4 \mathrm{~m}$ height along with $30 \mathrm{~m}$ width channel needs to construct to accommodate the flood. This recommended structural measure will decreases the 10-year return period flood extent by $69 \%$, 25-year return flood extent by $62 \%, 50$ year return period by $56 \%$ and 100 year return period by $51 \%$. The water depth also decreased considerably.

\section{Author Contributions}

Both of the authors substantially contributed to the conceptualization of this paper, choice of methodological analysis and figures. Abirham C. wrote the first draft and Sadnur W. did the digital elaboration of maps and cartographic representations. All authors have read and agreed to the published version of the manuscript.

\section{Funding}

This research has been funded by Ethiopian Environment and Forest Research Institute and Ethiopian Construction, Design and Supervision Works Corporation.

\section{Conflicts of Interest}

The authors declare no conflict of interests.

\section{Acknowledgements}

We would like to express our thanks to the Ethiopian Environment and Forest Research Institute for their financial support. Our thanks also go to the Central Statistical Agency, Ministry of Water Irrigation and Electricity, Ethiopia Mapping Agency, Ethiopia Metrological Agency, and Ethiopian Somali Region Unban Development Construction and Industry Bureau for their support on providing the required resource.

\section{References}

[1] World Meteorological Organization (1990). International Meteorological Vocabulary, WMO- NO: 182, draft second edition, Geneva, Switzerland.

[2] Sisir, P., \& K. Balan (2014). Flood risk mapping of Kadalundi river basin using GIS. International Journal of Scientific \& Engineering Research, 5 (7).

[3] Smith, K. (2001). Environmental hazards assessing risk and reducing disaster (3rd Ed.). Rutledge 11, New Fetter Lane: London.

[4] Bronstert, A. (2003). Floods and climate change: interactions and impacts. Risk Analysis, 23, 545-557.

[5] Hapuarachchi, H. A. P., Wang, Q. J., \& Pagano, T. C. (2011). A review of advances in flash flood forecasting. Hydro. Process, 25, 2771-2784.

[6] Olivera, F., \& Midment, D. (1999). System of GIS based hydrological and hydraulic application for highway engineering: Summary Report. Austin: University of Texas.

[7] Hydrologic Engineering Center (2013). HEC-RAS Manual. California: U.S. Army Corps of Engineers Hydrologic Engineering Center.

[8] Ouma, Y., \& Tateishi, R. (2014). Urban flood vulnerability and risk mapping using integrated multi-parametric AHP and GIS: methodological overview and case study assessment. Water, 6 (6), 1515-1545

[9] Weldegebriel M., Habtamu A., and Barana B. (2016). Dynamics of land use land cover chande and urbanization in Jigjiga town, Ethiopia. Somali regional state, eastern Ethiopia

[10] Fikre Z. and Abdurhman M. (2019). Land use land cover dynamics of eastern pastoral ranglands of Somali region, Ethiopia

[11] Central Statistical Agency (2013). Population projections for Ethiopia 2007-2037. Addis Ababa, Ethiopia: Author.

[12] Christian, W., 2007. Hand-book on statistical distributions for experimentalists. University of Stockholm: Particle Physics Group Fysikum.

[13] Hydrologic Engineering Center (2013). HEC-GeoHMS Technical Reference Manual. California: U.S. Army Corps of Engineers Hydrologic Engineering Center.

[14] United States Department of Agriculture, Natural Resources Conservation (1987). Urban Hydrology for Small watersheds. Technical Release 55. 
[15] Hydrologic Engineering Center (2013). HEC-GeoRAS Technical Reference Manual. California: U.S. Army Corps of Engineers Hydrologic Engineering Center.

[16] United Nation Environmental Protection (2002). State of the environment and policy retrospective
[17] O'Connell E., John E., Greg O'D., and Paul Q. (2007). Is there a link between agricultural land use management and flooding? 